\title{
A circular economy approach is needed for electric vehicles
}

\author{
Electric vehicles could help reduce greenhouse gas emissions and deliver a sustainable transport system. But the \\ full life cycle of electric vehicles needs to be considered in order to avoid creating resource issues while trying to \\ achieve the necessary climate goals.
}

\section{Jessika Luth Richter}

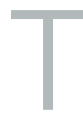
he future of mobility - and road transport in particular - is a topic of increasing focus for governments across the globe as they seek to reduce greenhouse gas emissions in compliance with the Paris Agreement and limit other pollutants that cause negative health effects. The transition to more sustainable transportation, which is required to achieve such reductions, is fuelling a rise in electric vehicle sales that is likely to accelerate in the coming years. But while electrification of transport is certainly needed, manufacturing electric vehicles is inherently resource intensive and it remains unclear whether the necessary resources will be available, at least in the short term, to meet this increasing demand.

The steel and aluminium used in the transport sector represent around $17 \%{ }^{1}$ and $27 \%^{2}$ of the global use of these materials respectively, most of it in vehicles; and the share of plastic in vehicle compositions continues to increase, bringing with it problems related to fossil fuel feedstocks ${ }^{3}$. Vehicles are also typically integrated with complex electronics (which is why the semiconductor chip shortage during the COVID-19 pandemic has led to delays in vehicle production). With electric vehicles, rare-earth magnets are required for many of the motor technologies, and other critical raw materials - including lithium, cobalt and graphite - are required for the batteries. Batteries account for a substantial proportion of the environmental impact of electric vehicles over their life cycle ${ }^{4}$ : materials such as lithium require extraction from sensitive and unique environments, while materials such as cobalt have social risks linked to the mining, such as child labour and conflicts ${ }^{5}$.

How best to deal with vehicles when their driving days are done is also a concern. The high metal content makes a good business case for vehicle end-of-life recycling for the metals. Processes are also now refined enough to recover and reuse a

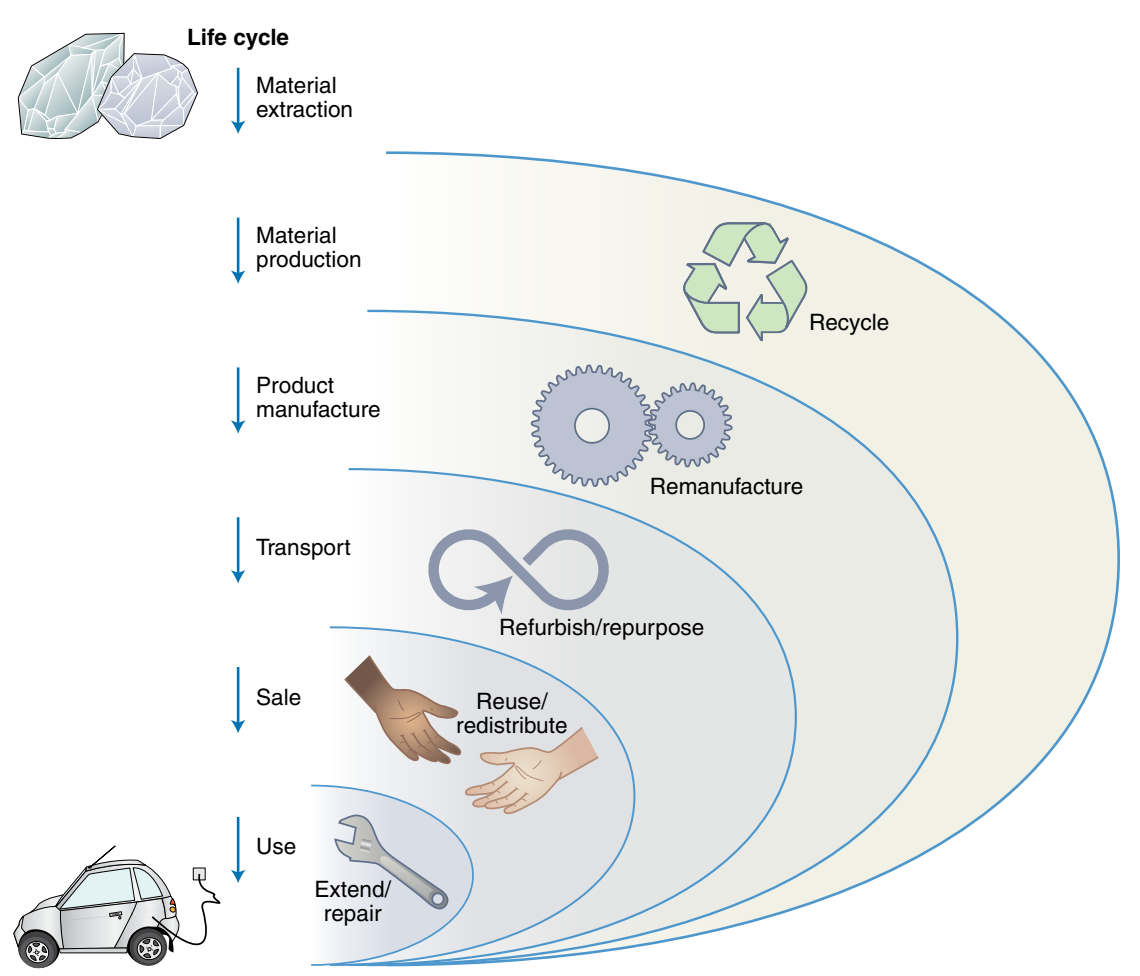

Fig. 1 | Circular strategies for electric vehicles. The useful lifetime of electric vehicles can be extended through repair and reuse. Refurbishing and remanufacturing can have lower environmental impact compared with manufacturing, and recycling materials can decrease the demand for mining of new primary materials.

high amount of the materials in traditional vehicles and their components, including batteries ${ }^{6}$. However, price fluctuations for secondary materials influence the business case and the increasing amount of residual material - which includes plastics, textiles, glass and critical metals - means that some material is still often wasted; the hazardous residual materials also pose risks if not properly managed.

To meet the resource and recycling challenges created by electric vehicles, the management of the end of life of such vehicles needs to start from the very beginning. A circular economy approach is, in particular, needed for electric vehicles in order to reduce their environmental impact and ensure that trade-offs are minimized in achieving the necessary climate goals.

\section{Current strategies and policies}

Circular strategies to deal with waste include reusing, repairing, refurbishing, remanufacturing and recycling (Fig. 1). There are already well-developed secondhand parts and car markets that can prolong vehicles' lifetimes, and a key question will be about optimal lifetimes 
and circular strategies, the nuances of which will change over time. There is a need to balance the environmental costs of extending the lifetime of internal combustion engine vehicles and less efficient electric vehicles with the environmental gains of sending these to recycling earlier to reuse components and materials to create more efficient electric vehicles. And as with other products, extending the lifetime of existing vehicles risks a delay in the take-up of new electric vehicles ${ }^{7}$. As well as strategies for repair and maintenance, there are also strategies for intensifying the first use of electric vehicles by using the idle capacity of the vehicle through car sharing schemes.

Recycling strategies for electric vehicles, and the policies driving them, are only just beginning to deal with changing vehicle technologies. It has been over 20 years since the end-of-life vehicle directive was introduced in the European Union, which created extended producer responsibility for vehicle manufacturers ${ }^{8}$. In practice, extended producer responsibility requires producers to take back their products for reuse, recycling or remanufacturing. It aims to reduce the life-cycle environmental impact of waste vehicles and also incentivize eco-designs that consider reuse and recycling from the start. Beyond the European Union, countries including Japan, Korea and China also have highly centralized, regulated systems for managing end-of-life vehicles.

Batteries, and components containing critical raw materials, are a key focus in developing circular economy strategies. There are reuse strategies for extending the life of electric vehicle batteries, following a hierarchy of strategies to optimize life-cycle value through direct reuse, repurposing, refurbishment and remanufacturing. Also, there are already markets for repurposing batteries in energy storage systems.

\section{Challenges with circularity}

Product policies to incentivize eco-design need to account for multiple, and sometimes conflicting, circular strategies in order to address resource issues. For example, substituting and decreasing the amount of critical materials can reduce the need for extraction, but it is also more difficult to recover small amounts of material later in recycling. Changing designs also creates a moving target, and there is a need for monitoring and flexibility of specific requirements; a key challenge for such policies is to balance a level of certainty with an ability to adapt to technological and market developments ${ }^{10}$.

So far, product policies have mainly focused on hardware products, but with increased electronic integration and vehicle autonomy, software can - and should also support circularity measures including longer lifetimes, repair and maintenance. The increasing need for specialized diagnostic tools and software related to hardware has, for instance, been noted as an impediment to repair and maintenance, if they are not easily accessible at reasonable cost ${ }^{11}$.

Extended producer responsibility and waste management policies have focused on managing hazardous waste and general recycling at least costs. Having targets only on recycling has sometimes resulted in incentivizing recycling over reuse strategies. The focus on economies of scale and cost reduction has also resulted in trade-offs with the quality of recycled materials. This could be the case with electric vehicles, where the demand for materials for new vehicles results in the recycling of these materials rather than prolonging their use in existing electric vehicles.

Even with extended-producerresponsibility systems in place, the data available are insufficient to fully understand the fate of the components and materials from vehicle waste, and it is estimated that there is still a considerable amount of secondhand cars and waste exported outside countries and regions with extended-producer-responsibility policies ${ }^{12}$. Electric vehicles and their components will also likely be exported to capture their substantial reuse and remanufacturing potential in lower-income countries ${ }^{13}$. This enables longer lifetimes and access to electric vehicles in lower-income countries, but it can also result in waste where waste management infrastructure is poorly developed - and parallels can be drawn to electronic waste. The anticipated demand for the materials - potentially also driven by regulation - could drive investment in better waste management in low-income countries or incentivize the re-export of the waste to recycling facilities that can extract the valuable materials.

Waste electric vehicle batteries pose challenges in terms of fires and hazardous contamination, and the recovery of resources requires environmentally sound recycling ${ }^{10}$. Under idealized conditions, it has been estimated that recycling end-of-life electric vehicle batteries could provide $60 \%$ of cobalt, $53 \%$ of lithium, $57 \%$ of manganese and $53 \%$ of nickel needed globally in $2040^{14}$. But we are currently far from such an ideal scenario. Unlike lead acid batteries, which are profitable for recycling, the recycling processes for electric vehicle batteries are still developing, and this, combined with current low volumes, means that recycling is mainly driven by regulation. Extended producer responsibility in the European Union, and waste management regulations in countries including China, Japan and India, have also specifically targeted electric vehicle batteries, but there remains a lack of effective policy in much of the world ${ }^{14}$.

\section{Outlook}

In 2020, the European Union proposed a new battery regulation ${ }^{15}$ that seeks to address many of the issues surrounding electric vehicles and represents the most ambitious policy to date. It aims to increase transparency, traceability and accountability across the battery life-cycle, it requires access to battery management systems, and it mandates digital passports, carbon footprint declarations and maximum thresholds. In addition to traditional extended-producer-responsibility targets for collection and recycling, it has specific recycling rates for lithium, cobalt and nickel, while also specifying targets for the use of recycled materials in new batteries to incentivize demand. Imposing specific material recycling has also been suggested for extended-producer-responsibility legislation for end-of-life vehicles as a whole ${ }^{16}$.

It has been suggested that such ambitious rules for electric vehicle batteries may increase costs and slow the adoption of electric cars ${ }^{17}$. But, arguably, increased supply-chain transparency should be incentivized generally. In addition, the transition to electric vehicles should still be driven, in large part, by policies phasing out fossil fuel vehicles and these potential trade-offs highlight the need for policy mixes and a systems approach. Increased costs could also incentivize sufficiency measures in transport (that is, discussion of mobility needs and what needs are met by electric vehicles versus other transport options) and minimize rebound effects in the transition to electric vehicles ${ }^{18}$. Circular economy discussions have been criticized for not adequately considering sufficiency measures, costs and just distribution of these $\operatorname{costs}^{19}-$ and these points will need to be carefully considered going forward.

Distribution of value, as well as distribution of costs, also needs to be discussed when designing circular economy policies and strategies for electric vehicles. Digital product passports are on political agendas and could be a key part of supplying better data, making supply chains more transparent and enabling collaboration between value-chain actors. Passports could potentially create recycling fees to follow the vehicle or component wherever it ends 
as waste and help with investment in sound waste and resource management systems. This could ensure that longer lifetimes for vehicles are not a trade-off with increased environmental impacts from poor waste management.

Circular economy strategies, in turn, also need to consider goals of climate policies. Limiting cross-border flows of used and waste vehicles in order to address leakage of circular economy value should be considered with regard to the needs of all countries to transition from fossil fuels. Such transfers of value can also help the development of sustainable mobility systems aligned with climate commitments. Specific country and regional economic competitiveness gains from circular economy strategies need to be balanced with the goals of addressing climate change globally. Ultimately, the transition to electric vehicles is likely to be more sustainable if approached from both climate and circular economy perspectives.

\section{Jessika Luth Richter (iD)}

Lund University, Lund, Sweden.

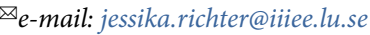

Published online: 31 January 2022

https://doi.org/10.1038/s41928-021-00711-9

References

1. World Steel Association. Steel Facts (2019); https://go.nature. com/3qYV2WD

2. All About Aluminium. Aluminium Applications: Aluminium in Transport; https://go.nature.com/3HG67mr

3. Esteva, L. C. A., Kasliwal, A., Kinzler, M. S., Kim, H. C. \& Keoleian, G. A. J. Ind. Ecol. 25, 877-889 (2021)

4. Harper, G. et al. Nature $575,75-86$ (2019).

5. Lèbre, É. et al. Nat. Commun. 11, 4823 (2020).

6. Despeisse, M., Kishita, Y., Nakano, M. \& Barwood, M. Procedia CIRP 29, 668-673 (2015)

7. Marcus, J. S., Zachmann, G., Gardner, S., Tagliapietra, S. \& Lykogianni, E. Promoting Product Longevity: How Can the EU Product Safety and Compliance Framework Help Promote Product Durability and Tackle Planned Obsolescence, Foster the Production of More Sustainable Products, and Achieve More Transparent Supply Chains for Consumers? (European Parliament, 2020).

8. European Parliament and Council. Directive 2000/53/EC of the European Parliament and of the Council of 18 September 2000 on End-of-Life Vehicles (2000); https://go.nature.com/3I2nf68

9. Albertsen, L., Richter, J. L., Peck, P., Dalhammar, C. \& Plepys, A. Resour. Conserv. Recycl. 172, 105658 (2021).
10. Baars, J., Domenech, T., Bleischwitz, R., Melin, H. E. \& Heidrich, O. Nat. Sustain. 4, 71-79 (2021).

11. Svensson-Hoglund, S. et al. J. Clean. Prod. 288, 125488 (2021). 12. Sakai, S. et al. J. Mater. Cycles Waste Manag. 16, 1-20 (2014).

13. Nasr, N. et al. Re-defining Value-The Manufacturing Revolution. Remanufacturing, Refurbishment, Repair and Direct Reuse in the Circular Economy (UN Environment Programme, 2018); https:// go.nature.com $/ 337 \mathrm{U} 4 \mathrm{P}$

14. Dunn, J., Slattery, M., Kendall, A., Ambrose, H. \& Shen, S. Environ. Sci. Technol. 55, 5189-5198 (2021).

15. EU Commission. Proposal for a Regulation of the European Parliament and of the Council Concerning Batteries and Waste Batteries, Repealing Directive 2006/66/EC and Amending Regulation (EU) No 2019/1020 (2020); https://go.nature. com/3Fo2wYF

16. Bhari, B., Yano, J. \& Sakai, S. J. Mater. Cycles Waste Manag. 23, 644-663 (2021)

17. Melin, H. E. et al. Science 373, 384-387 (2021).

18. Font Vivanco, D., Freire-González, J., Kemp, R. \& van der Voet, E. Environ. Sci. Technol. 48, 12063-12072 (2014).

19. Corvellec, H., Stowell, A. F. \& Johansson, N. J. Ind. Ecol. https:// doi.org/10.1111/jiec.13187 (2021).

Acknowledgements

This work is funded by the Swedish Research Council for Sustainable Development (Formas) project 'Circular

Economy: capturing value in waste through extended producer responsibility policies' (grant number 2017-01037).

Competing interests

The author declares no competing interests. 